\title{
Medusa Miti Üzerinden Sanatta Yeniden Anlamlandırma ve Yeniden Üretim
}

\author{
HAZAL ÜNSAL CORUK ${ }^{1}$ \\ ${ }^{1}$ PhD Candidate, Hacettepe University, Institute of Fine Arts, Sculpture (Orcid ID: 0000-0002- \\ 0704-399X)
}

\begin{abstract}
Özet
Bu çalışmada Medusa'nın sanat tarihindeki ifade biçimlerinin araştıııması amaçlanmaktadır. Makalenin "Medusa Miti ve Sanat Alanındaki Kullanımları” başlıklı birinci bölümünde Medusa mitine yer verilerek sanat tarihsel süreçteki çeşitli kullanımları ele alınmıştır. Medusa miti hem sanat tarihinde hem de feminizmde bir sembol olmuş ve üzerine birçok çalışma yapılmıştır. Sanatta feminist eleştiri bağlamında kadın sanatçılar ve sanat tarihçileri tarafından ele alınan Medusa, eril sistemin ötekileştirdiği ve kurban ettiği bir kadın olarak toplumsal cinsiyet ve feminizm hareketinde yer almıştır. Makalenin "Yeniden Üretim ve Yeniden Anlamlandırma" başlıkı ikinci bölümünde ise Medusa mitinden yola çıkılarak, yeniden anlamlandırma kavramına yer verilmiştir. Sanat tarihsel süreçte yeniden anlamlandırma Marcel Duchamp, Gerilla Kızlar, Özlem Şimşek gibi sanatçılar ile örneklendirilmiştir ve bazen sarayları koruyan, bazen çirkinleştirilerek gösterilen, bazen de güçlü olan olarak gösterilen Medusa, Benvenuto Cellini ve Luciano Garbati çalışmaları ile ele alınmıştır. Bir mit olarak Medusa'nın 1545-1554 tarihleri arasında Benvenuto Cellini tarafından yapılan bronzheykeli "Medusa Başı ile Perseus" adındadır ve döneminin başkaldırı hareketlerinden olan maniyerizmin en önemli örneklerindendir. Maniyerizm'de sanatçılar, abartıdan ve aşırılıktan ilham alırlar, Cellini'nin de Medusa mitinden yola çıkarak yaptığı "Medusa Başı ile Perseus" heykelinde Medusa'nın başından yılanların fırlaması ile klasik sanat anlayışına karşı bir başkaldırı olduğunun izlerini taşır. 2008 yılında Luciano Garbati, Cellini'nin heykelini yeniden ele alarak Medusa'nın hikayesindeki görünen rolleri "Perseus Başı ile Medusa" isimli heykeli ile tersine çevirmiş ve kadının toplumsal alandaki yeri bağlamında yeni tartışmalar oluşmuştur.
\end{abstract}

Anahtar Kelimeler: Medusa, yeniden üretim, yeniden anlamlandırma, feminizm, sanat 


\title{
Reinterpreting and Reproduction With the Medusa Myth
}

\begin{abstract}
The aim of this study is to investigate Medusa's ways of expressions in the history of art. In the first part of this study called "The Myth of Medusa and its Usage in Art", the myth of Medusa and its applications will be taken into account. The Medusa myth has been a symbol in both art history and feminism, and many studies have been done on it. Medusa, addressed by female artists and art historians in the context of feminist criticism in art, took part in the gender and feminism movement as a woman marginalized and sacrificed by the masculine system. In the second part, "Reproduction and Reinterpreting", the concept of reinterpreting will be applied to the myth of Medusa. Re-interpretation in the art historical process has been exemplified by artists such as Marcel Duchamp, Guerilla Girls, and Özlem Şimşek, Medusa which sometimes protects the palaces, is sometimes shown as disfigured, and sometimes shown as the powerful, has been dealt with by the works of Benvenuto Cellini and Luciano Garbati. As an myth Medusa is a production of male authority and one of its representation is created by Benvenuto Cellini between 15451554 as a bronz sculpture which is called "Perseus with the Head of Medusa" and an important example of rebellious genre of mannerism. The artists of mannerism are inspired by exaggeration and extremism and Cellini's "Perseus with the Head of Medusa" as an example of the myth of Medusa is a revolt against classical understanding of art with Medusa's head full of wild snakes. In 2008, Luciano Garbati reversed the apparent roles in Medusa's story with his sculpture "Medusa with the Head of Perseus" by reconsidering Cellini's sculpture, and new discussions occurred in the context of women's place in the social sphere.
\end{abstract}

Keywords: Medusa, reinterpreting, reproduction, feminism, art

Corresponding Author / Sorumlu Yazar

E-mail / E-posta

Manuscript Received / Gönderim Tarihi

Revised Manuscript Accepted / Kabul Tarihi

To Cite This Article / Kaynak Göster
HAZAL ÜNSAL CORUK

Hacettepe University, Institute of Fine Arts, Sculpture

PhD Candidate

unsalhazal@gmail.com

March 1, 2021/ 1 Mart 2021

April 11, 2021 / 11 April 2021

Ünsal Coruk, H. (2021). Medusa Miti Üzerinden Sanatta

Yeniden Anlamlandırma ve Yeniden Üretim. ViraVerita E-

Journal: Interdisciplinary Encounters, Vol.13,192-208. 


\title{
Medusa Miti Üzerinden Sanatta Yeniden Anlamlandırma ve Yeniden Üretim
}

\author{
"Saçlarım öfkeden kıvrıldı, aklımda sadece nefret kaldı, \\ Intikamı düşünmeye başladım ve sadece onun için yaşamaya. \\ Saçlarım yılanlar dönüştü, gözlerim dünyayı taştan \\ görmeye başladı." Ann Stanford
}

(Başkan, 2011, s.92)

\section{Medusa Miti ve Sanat Alanındaki Kullanımları}

Mitolojinin teogoni' mitlerinden birisi olan yılan başlı Medusa, ölümlü bir gorgo'dur ve gorgo'lar baktıkları kişileri taşa dönüştürmeleri ile bilinirler. Azra Erhat Gorgoları plastik sanatların alabildiğine faydalandıkları Gorgo'lar, Grai'lar gibi Phorkys'le Keton’un kızlarıdır şeklinde tanımlar (2021, s.118). Riyavetlere göre Medusa o kadar güzeldir ki tanrıçaların kıskançlığını, tanrıların beğenisini üzerine toplamıştır. "Rahibe olan Medusa, Denizler Tanrısı Poseidon tarafından, Athena'nın tapınağında tecavüze uğrar. Kendi kutsallığına yapılan bu saygısızlığa öfkelenen Athena, Medusa'yı bir canavara dönüştürerek lanetler." (Başkan, 2011, s.89). Medusa'nın bu lanet ile saçları yılana dönüşür. Medusa'ya yapılan zulümler bununla da bitmez ve Athena tarafından Zeus'un oğlu Perseus, Medusa'nın sürgün yeri olan Hyperborea'ya gönderilerek ondan Medusa'nın kafasını kesmesi istenir. "Ayna vazifesi gören bir bronz kalkanla kendisini koruyan Perseus, Medusa'nın başını keser; Gorgon'un kafasını tanrıça Athena'ya verir, o da bu başı kalkanının üstüne asar" (Hastings, 2018). Azra Erhat ise Perseus'un kahramanlık hikayesini aşağıdaki gibi anlatmıştır;

Perseus efsanesi dünyanın başka birçok folklorlarında bulunan masal motifleriyle süslüdür. Bu efsane şöyle özetlenebilir: Seriphossüs-kralı Danae'yi elde etmek ister, bu amaçla da Perseus'u başından atmaya çalışır. Delikanlıyı Medusa'nın kafasını kesmeye gönderir. Perseus yola koyulur, tanrilardan Hermes'le Athena onu Gorgo'lara bekçilik eden Graiaların yanına götürürler, Perseus bunları uyutup Gorgolara yaklaşmak yolunu bulur. Bu iş ancak kanatlı sandallar giymek ve başına Hades başlı̆ını geçirerek görünmez hale gelmekle olur. Tanrılar Perseus'a keskin çelikten bir orak da verirler, böylece Gorgoların karşına çıkar. Üç Gorgo'dan yalnız Medusa ölümlüdür, öbürlerine sataşmadan onu bulup öldürmek gerek. Perseus üç canavarı uyur bulur, kanatlı sandallarıyla havaya uçar ve Athena'nın Medusa'nın 
üstünde bir kalkanı ayna gibi tutmasından faydalanarak canavarın kafasını uçurur.

Medusa'nın kesik boynundan Pegasos atıyla Khrysaor fışkırır (Pergasos, Khrysaor) (2021, s.243).

Medusa miti yüzyıllar boyunca onlarca alanda kullanılmış, birçok eserin de öznesi olmuştur. Mimaride ise Medusa'nın bulunduğu yeri koruduğuna inanıldığı için önemli tapınaklara ve saraylara Medusa başı yerleştirilmiştir. Bu yüzden Yerebatan Sarnıcı'nda yer alan üç konumlu Medusa başı "Bizans'ta kılıç kabzalarına işlenmiş ve sütun kaidelerine (bakanların taş kesilmemesi için) ters olarak yerleştirilmiştir. Bir rivayete göre de Medusa'nın aynaya bakıp kendisini taşa çevirdiğine inanıldığı için, buradaki heykeli yapan heykeltraş ışığın yansıma açılarına göre Medusa'yı üç ayrı konumda yapmıştır" (kültür. İstanbul, 2020) (Görsel 1,2).

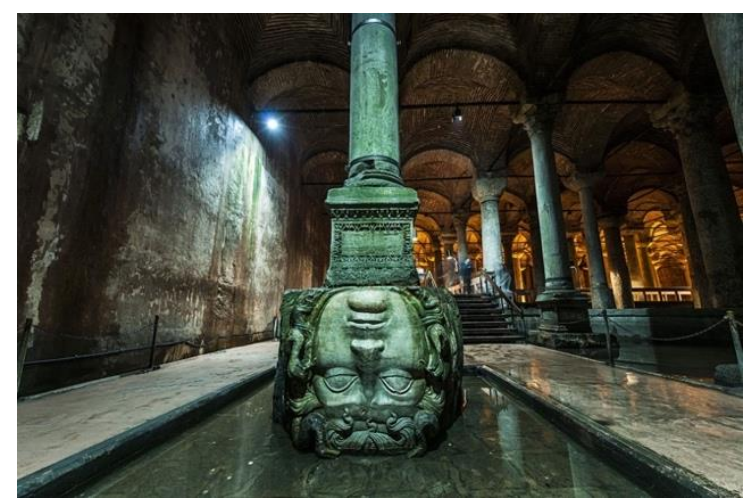

Görsel 1: Yerebatan Sarnıcı Ters Konumlandırılmış Medusa Başı. Kültür.istanbul Erişim: 15.01.2021. https://bit.ly/3agaNBv

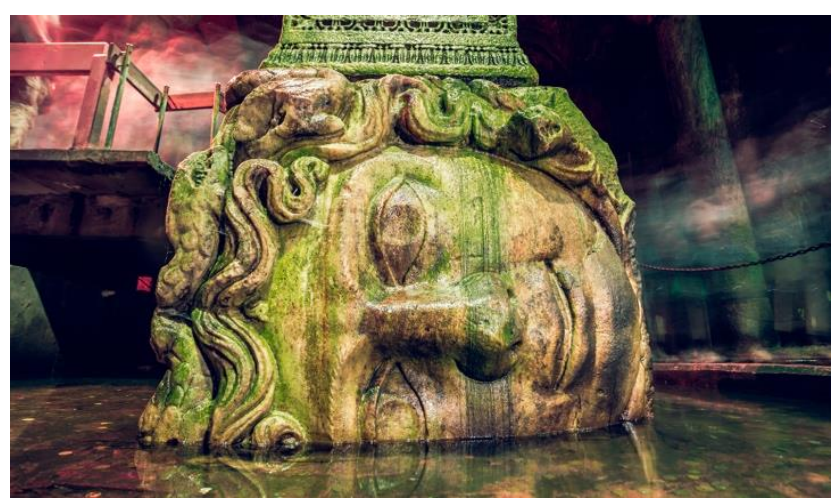

Görsel 2: Yerebatan Sarnıcı Yatay Konumlandırılmıș Medusa Başı. Kültür.istanbul Erişim: 15.01.2021. https://bit.ly/3agaNBv

Binlerce yıl öncesinden günümüze gelen hikâyede de yer aldığı gibi mitolojide mitler ve göstergeleri hem güç hem güçsüzlük hem eril iktidar hem yüceltme üzerine kurulmuş ve birbirine zıt daha onlarca inanışı beraberinde getirmiştir. Eril kahramanlık hikayesi ile Medusa ismi vahşetle anılmış ve toplumda yaratılan cinsiyet algısı ile bir paralellik içerisinde var olmuştur. "Medusa güzel olduğu için Poseidon'un tecavüzüne uğradı" çıkarımı yapılan bu hikâyede ceza dişil tarafa kesilmiştir ve toplumda bu durum kabul görmüştür. Christobel Hastings (2018) bu mit için toplumsal gerçeklik üzerinden "güçlü bir kadının tecavüze uğraması, şeytanlaştırılması, ardından da ataerkil toplum tarafından katledilmesi: Antik bir efsaneden ziyade modern bir gerçekliğe denk düşüyor" ifadelerini kullanmıştır.

Yirminci yüzyıla kadar eril taraflardan betimlenen Medusa miti çoğunlukla toplumsal bir yapının yansıması ile ele alınmasının yanısıra çirkinlik üzerine de kurulmuştur. Estetiğin ön 
planda olduğu modern öncesi dönemde çirkinlik sanat ontolojisinde yer almazken, çirkinliğin inşası ustaca gösterilmiştir. Görsel sanatlar alanında da kullanılan bu imgede çoğunlukla Medusa'nın ölüm anı, yüzündeki dehşet, kanlar ve yılanlar içerisindeki başı ile betimlenmiştir. Bu noktada Medusa'nın cezalandırılan karakter olarak betimlenmesinden, o'nun toplumsal yapıda özenilen bir kadın karakter olmaması için çirkin gösterildiği çıkarımı yapılabilmektedir (Görsel 3, 4). Başak Başkan’ın “Canavardan Kızkardeşe: Medusa Mitinin Yirminci Yüzyıl Kadın Şairleri Tarafından Tekrar Yazımı” isimli makalesinde ise Medusa betimlemelerini aşağıdaki ifadelerle açıklanmıştır;

Sanat yapıtlarında, Medusa daha çok korkutucu bir yüz ifadesi ile resmedilir. En ünlü özelliği ise, hiç kuşkusuz, kafasında saç yerine bulunan yılanlardır. Antik Yunan vazolarında da rastladığımız bu gizemli figür, Batı sanatında, Caravaggio, Rubens, Cellini, Rodin, Klee ve Picasso gibi bir çok sanatçıya ve heykeltraşa da ilham kaynağı olmuştur. Ayrıca, Euripides, Ovid, Dante, Petrarch, Goethe, Shelley, Nietzsche, Freud, Sartre ve Derrida gibi yazarlar ve filozoflar da eserlerinde Medusa 'dan bahsetmiş veya ona gönderme yapmışlardır. Birçoğu ondan bir canavar olarak söz ederken, bir kısmı onu karanlık bir ilham perisi olarak yorumlamış, bir kısım yazar ise Medusa 'dan kötü kaderli bir tecavüz kurbanı olarak bahsetmişlerdir (Başkan, 2011, s.88).

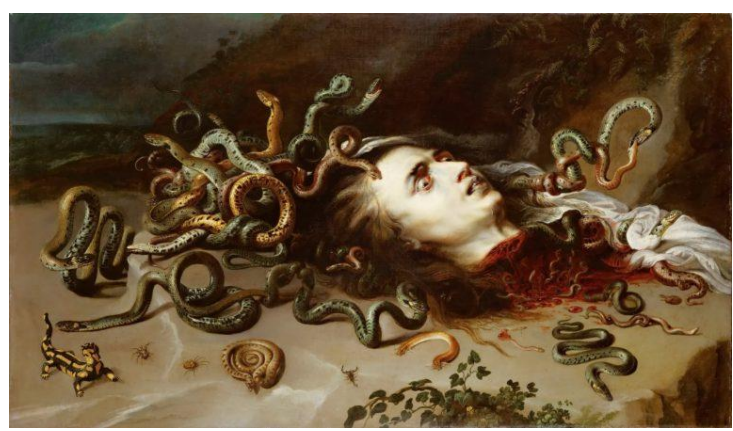

Görsel 3 : Peter Paul Rubens, Medusa Başı, Yaklaşık 1617-1618, Sanat Tarihi Müzesi. Wikipedia. Erişim: 15.01.2021. https://bit.ly/3jOVpzp

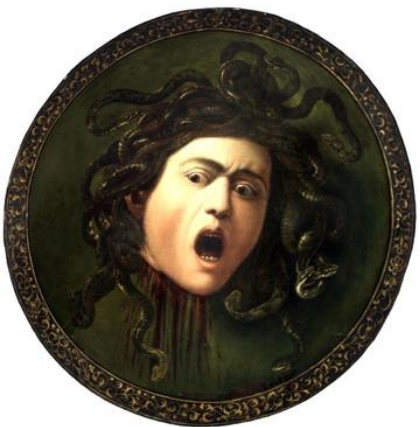

Görsel 4 : Caravaggio, Medusa-Murtola, 1596, Özel Koleksiyon. Wikipedia. Erişim: 15.01.2021. https://bit.ly/3jOVpzp

Mitolojik hikayelerde dahi güzelliğinden kaynaklı suçlanan ve cezalandırılan kadın, sanat alanında da 1960'lara kadar sadece resim, heykel vb. içerisinde figür olarak yer almıştır. Bu duruma artık sessiz kalamayan kadın sanatçılar, 1960'ların sonlarında hareketlenmeye başlayan siyasal aktivizm ve feminist hareketin artması ile Kadın Sanatçılar Devrimde (Women Artists in 
Revolution:WAR), Kadın Sanatçılar Geçici Komitesi (Ad Hoc Committee of Women Artists), Sanatta Kadınlar (Women in Arts) gibi müzelerde eril otoriteye ve yönetimine karşı oluşumlar kurmaya başlamışlardır (Antmen, 2012, s.19). 1971'de Linda Nochlin'in meşhur makalesi “Neden Hiç Kadın Sanatçı Yok?" ile de sanatta feminist eleştiri resmen başlamıştır.

Sanatta feminist eleştiri bağlamında kadın sanatçılar ve sanat tarihçileri tarafından ele alınan, kadının toplumsal cinsiyet ve toplumsal statü ile olan ilişkisindeki örneklerden birisini de Medusa miti oluşturmuştur. "Medusa, yirminci yüzyıl feminist hareket içinde, antik çağlarda yaşayan bir anayanlı toplum modelini savunan kurumların da etkisiyle ataerkil düzende kadınlığın öfkesinin ve gücünün simgesi olarak anlam kazanmıştır” (Başkan, 2011, s.88). Eril sistemin ötekileştirdiği ve kurban ettiği bir kadın imgesi olan Medusa, toplumsal cinsiyet ve feminizm hareketinde kendisine yer bulmaktadır. Feminist teorisyen Hélène Cixous, 1975 tarihli manifestosu Medusa'nın Gülüşü’nde “kadınların arzusu karşısında duydukları korku nedeniyle erkeklerin Medusa'yı bir canavara dönüştürdüğünü vurgular. Ona göre, eğer erkekler 'Medusa'ya doğrudan bakmaya' cesaret edebilseler, 'ölümcül değil çok güzel olduğunu ve kahkaha attığını görürlerdi'” ifadelerini kullanır (Hastings, 2018). Yirminci yüzyıla kadar ezilen, katledilen, cezalandırılan bir kadın olarak gösterilen Medusa, kadın hareketliliğinin hem toplumsal alanda hem de sanat alanında artması ile bir sembol haline gelmiştir. Bu noktada yirminci yüzyıla kadar güçsüzlüğü ve acizliği ile gösterilen Medusa artık güzelliği, koruyuculuğu ve gücü ile bir sembol olmaktadır.

Eril iktidarın bir yansıması olarak görülen Medusa bugün de birçok alanda varlığını sürdürmektedir. "The Powerpuff Girls 'deki dar elbiseli kötü kadın karakterden tutunda, UB40 grubunun İngiliz Başbakanı Margaret Thatcher'a dokundurduğu 'Madam Medusa' şarkısına kadar, Medusa efsanesi günümüz pop kültüründe etkisini sürdürüyor" (Hastings, 2018). 1960'larden sonra feminist literatürde ele alınan Medusa hem pop kültüründe hem de günümüzde sanatçıları tarafından da yeniden ele alınmaya başlamıştır. Bu tasvirlerde Medusa ötekileştirilen olarak değil, sahip çıkılan güçlü kadın imgesi olarak gösterilmektedir. Mitolojide gözüne bakılamayan Medusa'ya zıt olarak bugünün imgelerinde, Medusa'nın gözleri doğrudan izleyici üzerindedir ve tıpkı Hélène Cixous'nun (1975) bahsettiği gibi bakanlar Medusa'nın ölümcül bir varlık olduğunu değil, çok güzel olduğunu görmektedir. 2013'te pop kültürü simgelerinden Rihanna'nın Go Dergisi kapak çekiminde Medusa rolünde doğrudan kameraya odaklanarak izleyicinin gözüne bakması (Görsel 5), 2018 yılında günümüz sanatçısı Necla 
Rüzgar'ın Medusa büstünü ele alırken yine Medusa'nın gözlerini seyirciye yöneltmesi gibi (Görsel 6) yakın geçmiş örnekleri bulunmaktadır.

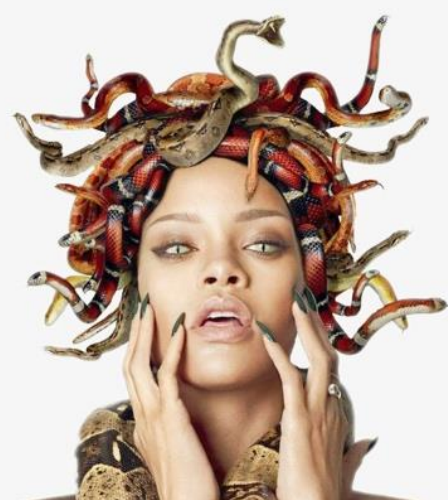

Görsel 5: Rihanna, Go Dergisi Kapak Çekimi, 2013. Seekpng. Erişim: 17.01.2021. https://bit.ly/3ddNqdW

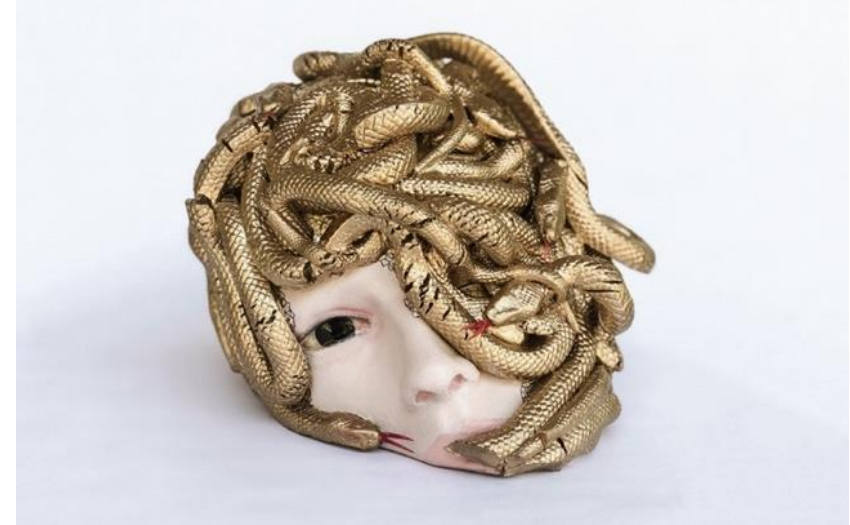

Görsel 6: Necla Rüzgar, Medusa, Çok Kalpli Varlık Sergisi, Galata Rum Okulu, 2018. Galeri Nev. Erişim: 17.01.2021. https://bit.ly/20yjbnr

\section{Yeniden Üretim ve Yeniden Anlamlandırma}

Medusa mitinin 1960'lar sonrası sanatçılar, sanat tarihçileri, edebiyatçılar ve daha birçok alanda yeniden üretimi yapılırken, yeniden anlamlandırmaya başvurulmuştur. Yeniden üretimin sanat alanındaki örneklerine bakıldığında modernizme kadar gitmek mümkündür. Walter Benjamin (2014) "Tekniğin Olanaklarıyla Yeniden Üretilebildiği Çağda Sanat Yapıtı" isimli makalesinde var olanı yeniden üretmekten ve çoğaltmaktan bahseder. Benjamin teknik ile yeniden üretimden bahsederken, geçmişte yapılmış olanın geleceğinde yeniden ele alınabilirliğini, bir şimdiyle ve onun geçmişi ile arasındaki ilişkiyi ele almaktadır. Benjamin "geçmişi tarihe uygun olarak yeniden konuşlandırabilmek, 'onu bir zamanlar gerçekten nasılsa öyle' anlamak olamaz, olmamalıdır." der (2015, s.160). Bu düşünceye paralel olarak geçmiş ile anın ilişkisi için Duchamp’ın 1919 tarihli L.H.O.O.Q çalışması ilginç bir örnek olabilir. Duchamp'ın Mona Lisa'yı yeniden ele alışı, tarihsel dönemlerin farklı yönlerinin algılanışıdır. Duchamp’ın L.H.O.O.Q isimli Dadacı yapıtı Da Vinci'nin Mona Lisa'sının bir röprodüksiyonu değil, tam da Modernizmin getirdiği bir yenilik ve karşıtlık unsuru olarak görünmektedir (Görsel 7, 8). Benjamin var olan ve eski arasındaki karşıtlığı Paris XIX. Yüzyılın Başkenti makalesinde aşağıdaki ifadeler ile açıklamıştır;

Yeni üretim aracının biçimi -ki başlangıçta henüz eskisinin biçiminin egemenliğindedir (Marx)- kolektif bilinçte yeninin eskiyle kaynaşmasını gösteren imgelerle örtüşmektedir. Bu imgeler özlem imgeleridir, kolektif bunlara dayanarak toplumsal ürünün hamlığını hem ortadan kaldırmayı hem nura boğmayı amaçlar. 
Yanı sıra, bu özlem imgelerinde kendisiyle eski arasında -oysa eski burada, daha dün geçerli olan demektir- bir karşıtlık yaratma yolunda kararlı bir çaba görülür (Benjamin, 2006, s.33).

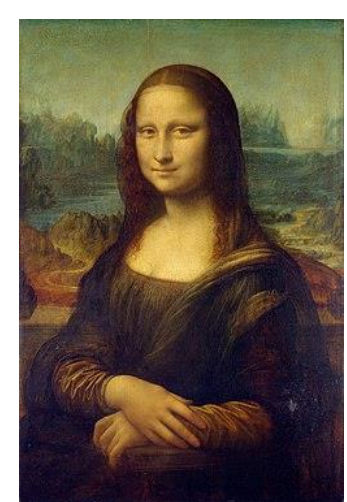

Görsel 7: Leonardo da Vinci, 1503, Mona Lisa. Wikipedia. Erişim: 19.01.2021 https://bit.ly/2WD1wvK

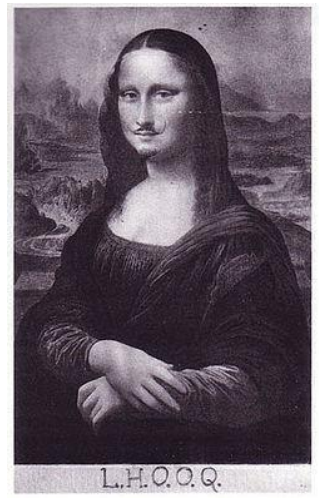

Görsel 8: Marchel Duchamp, 1919, L.H.O.O.Q. Wikipedia. Erişim: 19.01.2021 https://bit.ly/3rmxScn

Tıpkı Duchamp’ın L.H.O.O.Q çalışması gibi sanat tarihinde yeniden anlamlandırılan ve yeniden üretilen onlarca örnek vardır. Yeniden anlamlandırmalar, sanat eserlerinin ortak noktasını dönemin ruhuna göre şekillendirir. Örnek olarak Picasso 1957'de Diego Velazquez'ın 1656 tarihli Nedimeler'ini , Van Gogh 1889'da Delacroix'nın' 1850 tarihli Pieta'sını, Charles\& Marie Hilbert 1983'te Ingres'in 1862 tarihli Türk Hamamı'nı yeniden ele alarak kullanması verilebilir. Yeniden anlamlandırma tekniği ile görüntünün veya anın mevcut konjonktüre uygun şekilde yeniden ele alınması ile güncel biçimsel özellikler taşıyan yeni üretimler oluşmaktadır. Sanatsal üretimde yeniden ele alış, yeniden inşaayı doğurmuştur. Ali Akay, Nicolas Bourriaud'nun Postprodüksiyon adlı kitabının önsözünde yeniden anlamlandırmayı aşağıdaki ifadeler ile açıklar;

Sanatın orijinal değil de kopya üzerine oturması, yirminci yüzyııın modern sanatının bir verisidir. Günümüz küresel hiper tüketim ve kopyalama ve de aşırma, çalışma ilişkilerinde kendisini daha farklı bir boyuttan göstermektedir (...) Nasıl ki Duchamp sosyal olanı, kapitalist üretim biçiminin sanat alanına taşıdıysa, bugün de sanat kendisini üretimin sosyal alanına taşımaktadır (2004, s.10). 
Yeniden ifade biçimleri çoğu zaman kapitalist üretim biçiminin bir parçasını barındırırken çoğu zaman da provakatif bir şekilde ele alınmıştır. Bir grup Amerikalı Kadın Sanatçı'nın 1985'te bir araya gelerek oluşturduğu bağımsız bir feminist sanatçı insiyatifi olan Gerilla Kızlar (Guerrilla Girls) sanat kurumlarındaki cinsiyet ayrımını protesto eden bir dizi eser üretmişlerdir.

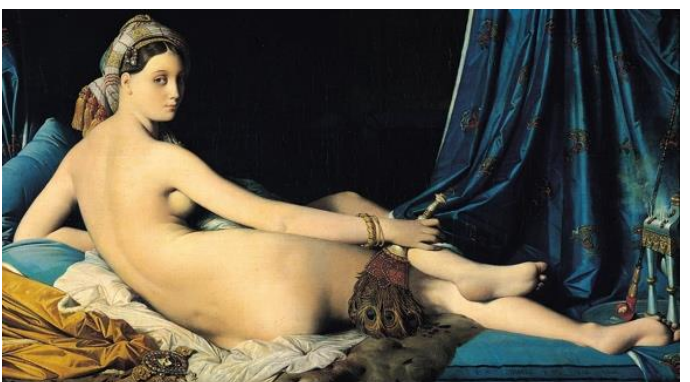

Görsel 9: İngress, Büyük Odalık, 1814,Tuval üzeri yağlıboya, Wikipedia. Erişim: 19.01.2021 https://bit.ly/2ZelNJd

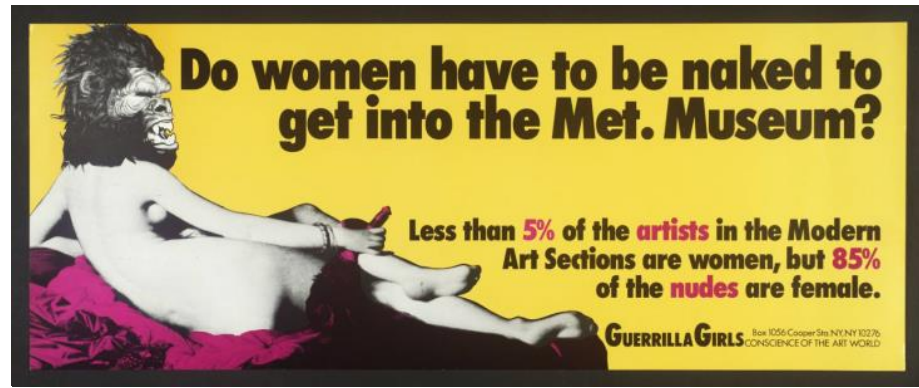

Görsel 10 : Guerilla Girls, Odalık, 1989, Dijital görüntü, E.Osman Erden. Erişim: 19.01.2021 https://bit.ly/3jRF10C

Linda Nochlin'in “Neden Hiç Büyük Kadın Sanatçı Yok?” sorusu gibi, Gerilla Kızlar insiyatifi de benzer bir tepki ile "Kadınların müzeye girebilmeleri için illa ki çıplak mı olmaları gerekir?" sorusunu sorarak ataerkil topluma tepkilerini göstermişlerdir. Gerilla Kızlar (Guerrilla Girls), "sanat tarihinde cinsiyet ayrımcı yaklaşımların kurduğu sahnelerin yıkılmasında feminizmi aktif bir araç olarak kullanmışlardır" (Antmen, 2012, s. 7). Gerilla Kızlar'ın sanat tarihi içerisindeki eril otoritenin kurduğu sahneleri yıkma çabası ve yeniden üretimin bir parçası haline getirmeleri, yeniden anlamlandırma meselesi için önemli bir örnek olmuştur ve kurdukları bu provakatif tavır ile sanat tarihine isimlerini yazdırmışlardır. (Görsel 9, 10)

Yeniden anlamlandırma sanat alanında Modernizmden beri Picasso, Van Gogh, Marcel Duchamp gibi çeşitli sanatçılar tarafından kullanılmıştır. Feminist sanatçıların da başvurduğu bu yöntem sanatçıların provakatif ve feminist eserlerini ortaya çıkartmıştır. Görsel sanatlarda olduğu kadar edebiyat alanında da yeniden anlamlandırma tekniği kullanılagelmiştir. Hélène Cixous 1975 yılında Arc dergisinin "Simone de Beauvoir ve Kadınların Mücadelesi" adlı özel sayısında yayınlanan Medusa'nın Kahkahası isimli denemesinde, kadınlığın negatif anlatıları üzerinden yeniden bir anlatı modeli oluşturur. Bu anlatılardan bir tanesi Freud'un kadını "kara kıta" olarak ele aldığı betimlemeyken bir diğeri ise Medusa Mitidir. Bilinen Medusa hikayesinde kimsenin Medusa'ya bakmaya cesareti olmazken, Cixous özellikle Medusa'nın gözlerine 
bakılarak onun güzelliğinin ve gülümsemesinin doğrudan görülmesi gerektiğinin altını çizer. Esra Başak Aydınalp de Medusa'nın Kahkasını açıklarken aşağıdaki ifadeleri kullanmıştır;

\begin{abstract}
Medusa kendisine bakmaya cesaret eden erkekleri taşa çevirir. Cixous'a göre, Medusanın direk gözlerine bakmak gerekir, Medusa ne ölümlüdür ne de gizemli aksine çok güzeldir ve gülümser. Bu metin kadını patriarkal sistem tarafından baskı altına alan yapıyı ortaya çıkararak yeniden canlandırır. Bu, kadınların sembolik sessizliklerini kırmak için kadınlara yapılmış bir çağrıdır ve onları yazıya davet eder. Çünkü Cixous'a göre kadının toplumsal örüntüdeki yerini değiştirmenin tek yolu yazıdan ve bununla beraber toplumsal belleğin yeniden inşasından geçer (2020 s.31).
\end{abstract}

Olanı yeniden yazmak ve yorumlamak, verilen dili tersine çevirerek yeniden düşünmeye ve farklı bir okumaya fırsat sağlamaktadır. Benjamin'in (2015) bahsetmiş olduğu geçmişi tarihe uygun olarak yeniden konuşlandırabilmek, ancak anın koşulları ile mümkündür. Bu koşullar içerisinde yakın geçmişte bile toplumsal yapı içerisinde kadın olmanın bir cinsiyet meselesi üzerinden tartışıması sanat alanında da bu meselenin kullanımının devamlılığını getirmektedir. Tıpkı 1989'da Gerilla Kızlar'ın bu meseleyi ele alışı gibi 2000'li yıllarda da günümüz sanatçılarından Özlem Şimşek de çalışmalarını toplumsal cinsiyet rolleri üzerinden ve kadın olmak üzerinden kurgular ve türk resmini yeniden yorumlayarak figürleri ve anlamları yeniden inşaa eder. Türk resminde modern Türk kadınının kimliği ve temsil edilişini sorgulayan Şimşek, geçmişin sanatı ve şimdinin sanatının arasındaki köprüyü kurar. Bu köprü yeniden anlamlandırma bağlamında feminist tutumu da beraberinde taşır. (Görsel 11,12) Ahu Antmen ise Özlem Şimşek'in çalışmalarını Kimlikli Bedenler kitabında aşağıdaki şekilde açıklar;

Şimşek'in yaklaşımı temsil otoritesinin kadınların (görsel) tarihi üzerindeki etkisini irdelerken parodik ifadeyi benimsemiş birçok başka kadın sanatçıyla yakınlık taşır. Burada vurgulanması gereken bir nokta, feminist bir yaklaşım bağlamında herhangi bir ifade biçiminin öznel bir yaratım biçimi olarak sahiplenilmesi karşısında ortak bir strateji olarak benimsenmesidir. Kadınların yeniden sunumunun ancak temsile ilişkin eleştirel bir anlayış sayesinde mümkün olabileceği düşüncesi üzerine temellenen bu sanatsal yaklaşım, Batı sanatında Lynda Benglis, Cindy Sherman, Sherrie Levine, Renee Cox gibi sanatçıların birbirinden farklı parodik yapıtlarını aynı zeminde buluşturur (2017, s.47). 


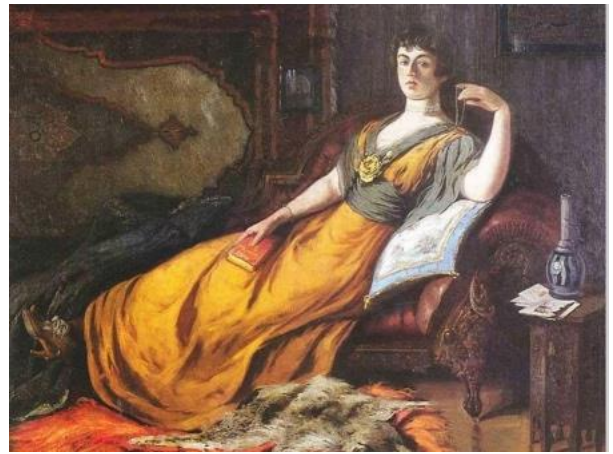

Görsel 11: Halife Abdülmecid Efendi, Haremde Goethe , 1917. Wikipedia. Erișim: 19.01.2021 https://bit.ly/3jQlRbW

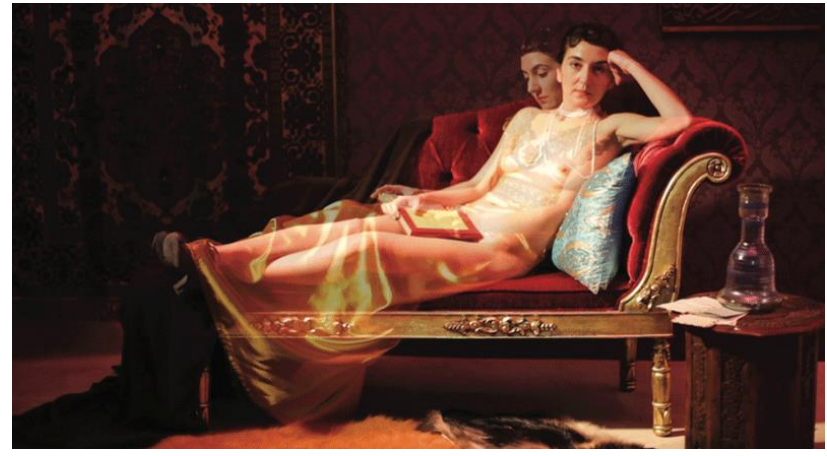

Görsel 12: Özlem Şimşek, Haremde Goethe (Abdülmecid Efendi'den Sonra), 2011. Kontrast Dergi. Erişim: 19.01.2021 https://bit.ly/20EbUCM

Figür olarak kadının sanat alanında kullanımı, temsil ve toplumsal cinsiyet sorunlarına odaklanır. Gerilla Kızlar'ın "Kadınların müzeye girebilmeleri için illa ki çıplak mı olmaları gerekir?" sorusuna dönülecek olunursa, kadınların müzelere sadece resim, heykel vs. gibi plastik alanlarda girebilmesi ve hatta bu temsiliyeti çıplaklık üzerinden ele alması dönemin toplumsal cinsiyet paradigmasını da gözler önüne serer. Özlem Şimşek'in de geçmiş eserleri yeniden canlandırması ve bugünün temsiliyetinde ele alması, ideolojideki hâkim gerçekliliği gösterir. "Temsil önceden belirlenmiş toplumsal cinsiyet kavramını yeniden sunarak farklılığı inşa eder" (Antmen, 2012, s.37).

Ontolojik olarak temsil meselesi sanatta önemli bir göstergeyken, yeniden anlamlandırma Antmen'in de altını çizdiği gibi yeniden inşayı barındırır. Bu noktada yeniden üretim bağlamında Medusa'ya tekrar dönüldüğünde 1554 tarihli Benvenuto Cellini'nin "Medusa Başı ile Perseus" heykeli ile 2008 tarihli Luciano Garbati'nin "Perseus Başı ile Medusa" heykel karşılaştırması günümüzde önemli bir örnek olarak durmaktadır. Cellini'nin 1545-1554 tarihinde döneminin klasik sanat anlayışına bir başkaldırı niteliği taşıyan Medusa heykelindeki göstergeler, Medusa miti üzerinden; aşırılık, abartı ve soyut imgelemi barındırır. 


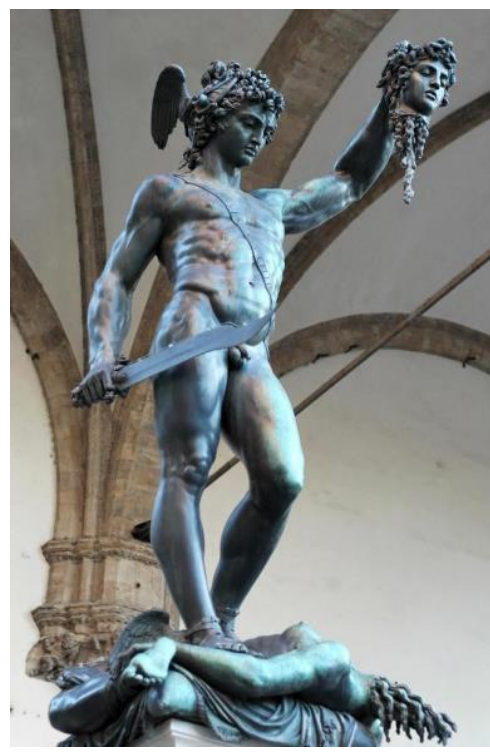

Görsel 13: Benvenuto Cellini, Medusa Başı ile Perseus / Perseus with the Head of Medusa, 1545-1554, Floransa

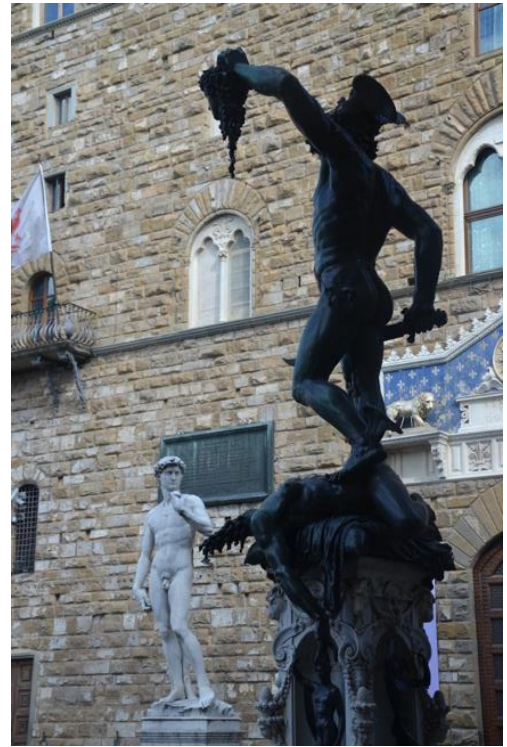

Görsel 14: Benvenuto Cellini, Medusa Başı ile Perseus / Perseus with the Head of Medusa, 1545-1554, Hazal

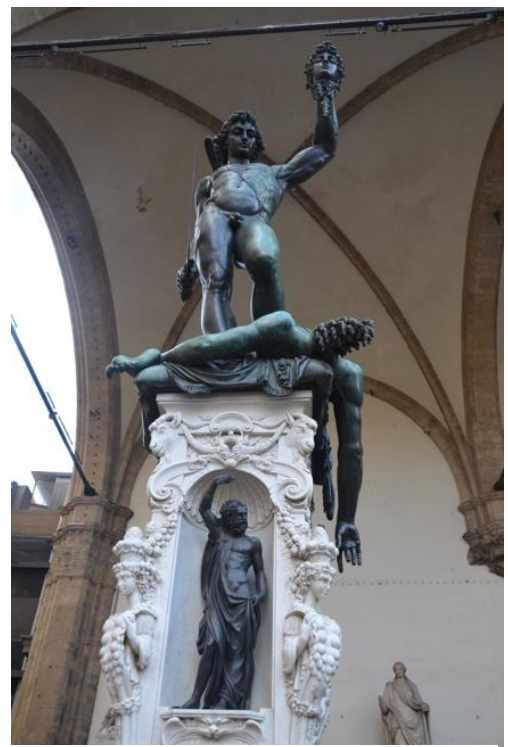

Görsel 15: Benvenuto Cellini, Medusa Başı ile Perseus / Perseus with the Head of Medusa, 1545-1554, Hazal Ünsal

2008 yılında Luciano Garbati tarafından tekrar ele alınan bu heykelde Gabarti değişen roller üzerine çalışmış ve "Medusa'nın bakış açısından hayal edip canavarın arkasındaki kadını ortaya çıkarabilecek bir heykel olarak" tasarlamıştır (Jacobs,2020). Medusa'nın hikayesini tamamen tersine çevirdiği ve galip tarafın Medusa olarak gösterildiği bu heykel için Gabarti; “Cellini’nin heykelinden çok etkilendiğini ve efsanenin arkasındaki kadını insanlaştırmak ve bir canavar olarak kimliğini sorgulamak istediği" ifadelerini kullanır (Cascone, 2020).

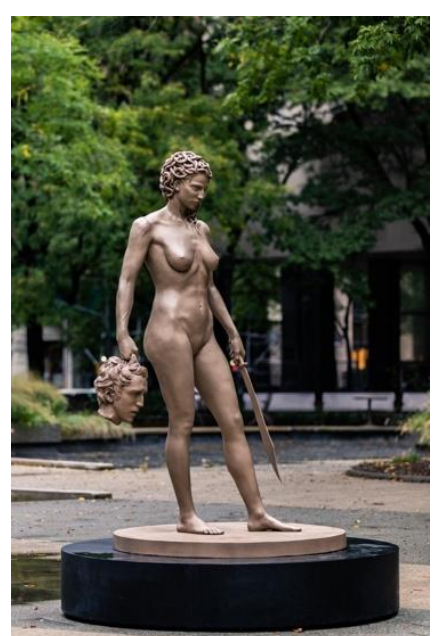

Görsel 16: Luciano Garbati, Perseus Başı ile Medusa / Medusa with the Head of Perseus, 2008, The New York Times, Erişim: 25.01.2021 https://nyti.ms/3qXKcPu

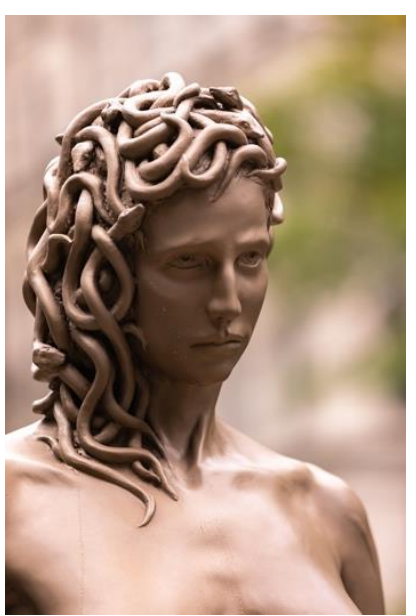

Görsel 17: Luciano Garbati, Perseus Başı ile Medusa / Medusa with the Head of PerseusDetay, 2008, The New York Times, Erişim: 25.01.2021 https://nyti.ms/3qXKcPu 
1970'lerden beri modern feminist harekette Medusa'nın toplumsal bilinci değiştirme çabası, Rihanna'nın bir magazin dergisinde yer alan kapak çekimindeki gibi veya Necla Rüzgar'ın Medusa büstünü kullanması gibi daha birçok alanda çeşitli çalışmalarda kullanılmıştır. Medusa mitini ele alan sanatçılardan farklı olarak Luciano Garbati'nin Medusa heykeli, 2017 yılında cinsel saldırı ve cinsel tacize karşı bugünün gerçekliği olan sosyal medyada ortaya çıkan \#metoo ${ }^{\mathrm{ii}}$ hareketine adanmıştır. Bu adanma, sanat tarihsel süreçte sanatın yeniden ele alınışının toplumsal yapı ile paralelliğini açıklamaktadır. Cinsel tacize ve saldırıya uğrayan kadınların \#metoo etiketi ile sosyal medyada yapılan paylaşımları tacizin Medusa'dan bugüne devam ettiğinin var olduğunu tüm dünyaya göstermiştir. 1545 tarihli Cellini heykeli Medusa mitinin bir temsili iken 2008 tarihli Gabarti heykeli kendi çağının ve toplumunun bir göstergesi olarak boyut kazanmaktadır. Anlatıların ve hikayelerin tersine döndüğü bu eserde kadının toplumsal alandaki yeri, metoo hareketi kapsamında bugünün gerçekliğinde ele alınmakta ve toplumsal belleğin yeniden inşa çabasını sunmaktadır. Yüzyıllardır toplumsal düzenin eril merkezli olmaya devam edişi, Garbati'nin tasvirinde Perseus'un başının Medusa'nın elinde oluşu ile boyut bulmaktadır. Garbarti ise çalışmadaki biçimsel ifadeleri "Medusa dingin ama bitap düşmüş vaziyette, Perseus'un başını ve kılıcını taşımak zorunda olduğu yüklermiş gibi tutuyor, duruşu, bir yere doğru ilerliyormuş gibi." şeklinde tanımlamaktadır (Sipahioğlu,2020). Medusa mitinin gerçekliğinin ve temsilinin sorgulandığı bugünün toplumsal yapısı ile Gabarti'nin heykeli yaşamın her alanında tacize uğrayan kadınlar ve kadın hareketleri tarafından da sahiplenilmektedir.

Garbati'nin "Medusa Başı ile Perseus” heykeli toplumsal hareketliliğin yanısıra birçok tartışmayı da beraberinde getirmiştir. Kuşkusuz çıkan tartışmalar sanatsal eleştiri bağlamında değil, metoo hareketine uygunluğu üzerinden biçimsel bir şekilde olmuştur. Yeniden anlamlandırma açısından sanat tarihsel süreçte sorun görünmeyen bu çalışma bir kitlesel ve toplumsal harekete adandığında siyasal ve feminist aktivizm litaratüründe açıklamalara ihtiyaç duymaktadır. Hareket içerisinden “cinsel saldırı mağdurlarının bir kısmı, Medusa’nın toplum dışı bir intikamcı olarak sunulmasından rahatsız olduklarını belirtmişlerdir. Buna ek olarak diğer tartışmalardan birisi ise Heykelde Medusa'anın neden Poseidon'un (tecavüzcüsünün) değil de Perseus'un (celladının) kafasını taşıdığıdır. Ancak Gabarti'nin bu noktada "sadece rolleri değiştirdim" ifadesi Medusa'nın hem intikamcı olarak gösterilmediğinin hem de neden Perseus'un kafasını taşıdığının cevabı niteliği taşıyor. Buna ek olarak anti-feminist argümanlar, 
kadın bedeninin sunumu gibi sanat eleştirisinden uzak tartışmalara da yol açmıştır" (Sipahioğlu,2020).

Gündelik yaşam mekanizması içerisinde gelişen ve değişen toplumsal davranışlar kuşkusuz sanat, edebiyat, felsefe ve daha birçok alanı da doğrudan etkilemiştir. Her alanda olduğu gibi mutlaklık arayışında olan sanatçılar ve düşünürler, mevcut döneme göre eserlerini anlamlandırmış ve üretmişlerdir. Eski düşünce ve hikâyeye karşılık anın gerçekliğinde yenilik arayışı hâkim olmuştur.

\section{Sonuç}

Mitolojik öğeler sanat alanında yüzyıllar boyunca kullanılmış ve kullanılmaya devam etmektedir. Bunlardan birisi olan Medusa mitinin hem feminist harekette hem de sanat tarihinde önemli örnekleri bulunmaktadır. Yüzyıllardır farklı alanlarda ele alınan Medusa miti eril baskınlığından kaynaklı diğer mitinden ayrılmıştır. 1960'lardan sonra siyasal aktivizmin ve feminist hareketin canlanması ile daha çok feminist eleştiri bağlamında ele alınanan Medusa miti gibi yüzlerce masal yıllardır süregelen ve birçok alanda kullanılan anlamlandırma, temsil yaratma, -mış gibi yapma gibi teknikler ile yeniden ele alınmıştır.

Antik dönemlerden beri yeniden ele alma, yirminci yüzyılın başlarına kadar bir gelişim tekniği olan röprodüksiyon olarak adlandırılırken, Duchamp’ın Mona Lisa'yı yeniden ele alarak geçmiş ile anın ilişkisini kurması, sanatta yeni ifade biçimlerinin doğuşunun sinyallerini vermiştir. 1960'lara gelince Andy Warhol'un Brillo kutuları, Marilyn Monroe, Mao gibi birçok popüler figür ve ürünü çoğaltım teknolojisi ile ele alması ile teknikten ziyade bir sanatçı tavrına dönüşmüştür. Sanat tarihsel süreçte yeniden üretim ve anlamlandırmaların bir toplumsal mesele ile doğrudan ilişkili oluşunun örnekleri ise Gerilla Kızlar'ın: İngress, Odalık tablosu ile çok net görülmektedir. Yeniden üretim ve yeniden anlamlandırma 1960 'lardan sonra feminist hareketin de artması ile geçmişte kadınların toplumsal yapı ve sanat alanında bulunduğu yerlerin eleştirisi bağlamında feminist sanat literatüründe kullanılmıştır.

21. yüzyılda hem toplumsal yapının değişimi hem de yeniden üretimin ve anlamlandırma ile sanat alanına yansımaları da ciddi seviyede artış göstermiştir. Luciona Garbati’nin yeniden anlamlandırma ve rolleri tersine çevirme bağlamında ürettiği 2008 tarihli "Medusa with the Head of Perseus" heykeli yapımından on sene sonra Medusa hikayesinin kaçınılmaz 
anlamlarından kaynaklı metoo isimli feminist hareketin simgelerinden olmuştur. Gabarti tarafından Yunan mitolojiinden olan Medusa'nın hikayesel anlatımını alt üst edilerek yeniden inşası kurulmuştur.

\section{ORCID ID}

HAZAL ÜNSAL CORUK

(ID) (Orcid ID: 0000-0002-0704-399X)

\section{Declaration of Conflicting Interests}

The author declared that there were no conflicts of interest with respect to the authorship or the publication of this article.

\section{Çıkar Çatışması Beyanı}

Yazar bu makalenin yazarlık veya yayımlanmasına ilişkin olarak hiçbir çıkar çatışması olmadığını beyan etmiştir.

\section{KAYNAKÇA}

Akan, E. Gürhan, N. (2020). Feminizmin "E- Hali": Dijital Feminizm Üzerine Bir Araştırma. Hafıza Uluslararası Sosyal Bilimler Dergisi, C.2/2, S.4-22

Antmen, A. (2012). Sanat Ve Cinsiyet. İstanbul: Illetişim

Antmen, A. (2017). Kimlikli Bedenler. İstanbul: Sel Yayıncılık

Aydınalp, E.B. (2020). Hélène Cıxous'ta Dişil Yazı: "Oıdıpus'un Adı-Yasaklanmış Bedenin Şarkısı" Ve "Dora'nın Portresı" Adıı Eserlerinin Yapısökümü, Edebî Eleştiri Dergisi, C. 4/1, S.2637

Başkan, F. B. (2011). Canavardan Kızkardeşe: Medusa Mitinin 20. Yy Kadın Şairleri Tarafından Tekrar Yazımı, Ankara: Edebiyat Ve Bilim-I, Iı. Uluslararası Edebiyat Ve Bilim-I Sempozyumu Bildirileri. S.88-97.

Benjamin, W. (2014), Pasajlar, (Çev: Ahmet Cemal), İstanbul, Yapı Kredi Yayınları

Benjamin, W. (2006). Paris Xıx. Yüzyılın Başkenti, Enis Batur (Haz). Modernizmin Serüveni (S.3241) İstanbul: Alkım Yayınevi.

Benjamin, W. (2015). Estetize Edilmiş Yaşam. (Ü. Oskay, Çev.). İstanbul: İnkılap Yayınları Bourriaud, N. (2004), Postprodüksiyon. (N. Saybaşlı, Çev.), İstanbul: Bağlam Yayıncılık 
Cascone, S. (2020). "The Artist Behind A (Very Questionable) Nude Public Statue Of Medusa As A Feminist Avenger Defends His Work" 25.02.2021 Tarihinde Https://Bit.Ly/3kvj9se Adresinden Alındı.

Erhat, A. (2021). Mitoloji Sözlüğg̈, İstanbul: Remzi Kitabevi

Hastings, C. (2018), Medusa Efsanesi: Tecavüz Kurbanının Canavara Dönüştürülmesi, 01.02.2021 Tarihinde Başlangıç Dergi Sitesi: Https://Baslangicdergi.Org/MedusaEfsanesi/ Adresinden Alındıç

Jacobs, J. (2020) "How A Medusa Sculpture From A Decade Ago Became \#Metoo Art" 25.02.2021 Tarihinde Https://Nyti.Ms/3soytes Adresinden Alındı.

Sipahioğlu, C. (2020), Metoo Hareketine Adanan Medusa Heykeli Tartışma Yarattı, 01.02.2021 Tarihinde Kayıp Rıhtım Sitesi: Https://Kayiprihtim.Com/Haberler/Sanat/MetooHareketi-Medusa-Heykeli-Tartisma/ Adresinden Alındı.

(2020), Yerebatan Sarnıcı, 01.02.2021 Tarihinde Kültür İstanbul Sitesi:

Https://Kultur.İstanbul/Yerebatan-Sarnici-Muzesi Adresinden Alındı.

\section{Görsel Dizini}

Görsel 1: Yerebatan Sarnıcı Ters Konumlandırılmış Medusa Başı. Kültür.istanbul Erişim:

15.01.2021. https://bit.ly/3agaNBv

Görsel 2: Yerebatan Sarnıcı Yatay Konumlandırılmış Medusa Başı. Kültür.istanbul Erişim:

15.01.2021. https://bit.ly/3agaNBv

Görsel 3 : Peter Paul Rubens, Medusa Başı, Yaklaşık 1617-1618, Sanat Tarihi Müzesi.

Wikipedia. Erişim: 15.01.2021. https://bit.ly/3jOVpzp

Görsel 4 : Caravaggio, Medusa-Murtola, 1596, Özel Koleksiyon. Wikipedia. Erişim: 15.01.2021. https://bit.ly/3jOVpzp

Görsel 5: Rihanna, Go Dergisi Kapak Çekimi, 2013. Seekpng. Erişim: 17.01.2021.

https://bit.ly/3ddNqdW

Görsel 6: Necla Rüzgar, Medusa, Çok Kalpli Varlık Sergisi, Galata Rum Okulu, 2018. Galeri Nev.

Erişim: 17.01.2021. https://bit.ly/2Oyjbnr

Görsel 7: Leonardo da Vinci, 1503,

Mona Lisa. Wikipedia. Erişim: 19.01.2021 https://bit.ly/2WD1wvK

Görsel 8: Marchel Duchamp, 1919, L.H.O.O.Q. Wikipedia. Erişim: 19.01.2021

https://bit.ly/3rmxScn 
Görsel 9: İngress, Büyük Odalık, 1814,Tuval üzeri yağlıboya, Wikipedia. Erişim: 19.01.2021 https://bit.ly/2ZelNJd

Görsel 10: Guerilla Girls, Odalık, 1989, Dijital görüntü, E.Osman Erden. Erişim: 19.01.2021 https://bit.ly/3jRF10C

Görsel 11: Halife Abdülmecid Efendi, Haremde Goethe , 1917. Wikipedia. Erişim: 19.01.2021 https://bit.ly/3jQIRbW

Görsel 12: Özlem Şimşek, Haremde Goethe (Abdülmecid Efendi'den Sonra), 2011. Kontrast Dergi. Erişim: 19.01.2021 https://bit.ly/2OEbUCM

Görsel 13: Benvenuto Cellini, Perseus with the Head of Medusa, 1545-1554, Floransa Wikipedia. Erişim: 25.01.2021 https://bit.ly/20yndw5

Görsel 14: Benvenuto Cellini, Perseus with the Head of Medusa, 1545-1554, Floransa, Hazal Ünsal, Kişisel Erişim: 2015

Görsel 15: Benvenuto Cellini, Perseus with the Head of Medusa, 1545-1554, Floransa, Hazal Ünsal, Kişisel Erişim: 2015

Görsel 16: Luciano Garbati, Medusa with the Head of Perseus, 2008, The New York Times, Erişim: 25.01.2021 https://nyti.ms/3qXKcPu

Görsel 17: Luciano Garbati, Medusa with the Head of Perseus-Detay, 2008, The New York Times, Erişim: 25.01.2021 https://nyti.ms/3qXKcPu

\section{Sonnotlar}

\footnotetext{
¡ Teogoni: Mitolojinin dört ana bölümünden biridir ve tanrıların nereden geldiğini anlatır.

ii 24 Ekim 2017'de Twitter'da trend olan \#MeToo (\#BenDe) hashtag'i aktris Alyssa Milano'nun, Hollywood yapımcısı Harvey Weinstein'ın cinsel taciz iddialarına yanıt olarak gündeme girmiş ve büyük bir ilgi görmüştür. 24 saat içinde hashtag 12 milyon kez kullanılmıştır. (Akan, Gürhan, 2020, s.20)
} 